\title{
Antiviral therapy improves the survival rate and decreases recurrences and fatalities in liver cancer patients following curative resection: A meta-analysis
}

\author{
HAO ZHANG ${ }^{1}$, YUCHEN ZHOU ${ }^{2}$, GUOSHENG YUAN ${ }^{1}$, GUANGYAO ZHOU ${ }^{1}$, \\ DINGHUA YANG ${ }^{2}$ and YUANPING ZHOU ${ }^{1}$
}

\begin{abstract}
${ }^{1}$ State Key Laboratory of Organ Failure Research, Guangdong Provincial Key Laboratory of Viral Hepatitis Research, Department of Infectious Diseases; ${ }^{2}$ Department of Hepatobiliary Surgery, Nanfang Hospital, Southern Medical University, Guangzhou, Guangdong 510515, P.R. China
\end{abstract}

Received February 13, 2015; Accepted June 11, 2015

DOI: $10.3892 / \mathrm{mco} .2015 .614$

\begin{abstract}
The present study aimed to investigate the impact of postoperative antiviral treatment on tumor recurrence, fatalities and survival of patients with chronic hepatitis B virus (HBV) infection-related primary hepatocellular carcinoma (HCC). A systematic meta-analysis was performed. All the studies comparing nucleos(t)ide analogues (NAs) versus placebo or no treatment were considered. The results were expressed as relative ratio (RR) for 1-, 3- and 5-year recurrence-free survival (RFS) and overall survival (OS), recurrence $\mathrm{HCC}$ and fatalities with $95 \%$ confidence intervals (CI) using STATA 11.0. In total, 15 trials with 7,619 patients were included. There were significant improvements for 1-, 3- and 5-year RFS (RR, 1.09; P=0.003; RR, 1.202; $\mathrm{P}<0.001$; and $\mathrm{RR}, 1.219 ; \mathrm{P}=0.02$; respectively) and in 3- and 5-year OS (RR, 1.087, $\mathrm{P}=0.006$; and $\mathrm{RR}, 1.186 ; \mathrm{P}<0.001)$ in the NAs group compared with the control group. Sensitivity analyses confirmed the robustness of the results. In addition, the significantly high rate of recurrence $\mathrm{HCC}$ and fatalities existed in the control group (RR, 1.301; $\mathrm{P}=0.002$; and $\mathrm{RR}, 1.816, \mathrm{P}<0.001)$. One study was for an entecavir (ETV)-treated group compared with an adefovir
\end{abstract}

Correspondence to: Professor Yuanping Zhou, State Key Laboratory of Organ Failure Research, Guangdong Provincial Key Laboratory of Viral Hepatitis Research, Department of Infectious Diseases, Nanfang Hospital, Southern Medical University, 1838 North Guangzhou Avenue, Guangzhou, Guangdong 510515, P.R. China

E-mail: yuanpingzhou@163.com

Professor Dinghua Yang, Department of Hepatobiliary Surgery, Nanfang Hospital, Southern Medical University, 1838 North Guangzhou Avenue, Guangzhou, Guangdong 510515, P.R. China E-mail: dhyang5810@yahoo.com

Key words: hepatitis B virus, hepatocellular carcinoma, curative, antiviral, meta-analysis
(ADV)-treated group and lamivudine (LAM)-treated group. The 3-year disease-free survival rate for the ETV group was significantly better compared with the ADV and LAM groups [hazard ratio (HR), 0.810; $\mathrm{P}=0.049$; and $\mathrm{HR}, 0.737 ; \mathrm{P}=0.007$ ]. The present study demonstrated the beneficial effects of NAs therapy following curative treatment of HBV-related HCC. ETV may be the superior choice compared to ADV or LAM for the antiviral treatment.

\section{Introduction}

Hepatocellular carcinoma (HCC) ranks as the third cause of cancer-related fatality worldwide. An estimated 748,300 new HCC cases and 695,900 fatalities occurred worldwide in 2008 (1). Hepatitis B virus (HBV) infection or HCV infection is one of the major risk factors for the development of HCC, particularly in Eastern Asia and sub-Saharan Africa. It has been estimated that HBV infection is associated with 50-80\% of HCC cases worldwide. Increasing evidence indicates that antiviral therapy with nucleos(t)ide analogue (NA) drugs is effective in reducing the incidence of HCC in HBV-infected patients (2).

Surgery, ablation and liver transplantation are the potentially effective treatments for $\mathrm{HCC}$, although the long-term survival rate remains unsatisfactory, due to high recurrences in $36.8-78.0 \%$ of postoperative patients (3). Recently, a meta-analysis showed the benefits of adjuvant NAs therapy following curative treatment of HBV-related HCC based on the recurrence-free survival (RFS) and overall survival (OS) (4). However, this study did not show the exact 1-, 3- and 5-year RFS and OS, or the HCC recurrence and mortality rates in patients following surgery between the antiviral treatment and control groups. Five NAs have been licensed to treat patients with HBV infection. Few studies have described which type of NAs was the best for the HCC patients. Based on these reasons, the present meta-analysis was performed to focus on the effect of 1-, 3- and 5-year RFS and OS, HCC recurrence and mortality rates between patients by adjuvant NAs therapy following curative treatment of HBV-related HCC, and which NA is the best for these patients. 


\section{Materials and methods}

Literature search. The present study was performed according to the recommendations of the PRISMA statement (5). Computerized searches were conducted on Web of Science and PubMed until 1 November, 2014. The strategy was based on MeSH terms combining with free text words. The detailed search strategies were as follows: (HCC OR liver cancer OR hepatic carcinoma OR hepatocellular carcinoma) AND [hepatectom* OR (liver* OR hepatocellular* OR hepatic OR hepato-cellular and resection) OR postoperative OR surgery] AND (nucleoside OR nucleotide and analogue*) AND [lamivudine (LAM) OR adefovir (ADV) OR entecavir (ETV) OR telbivudine OR tenofovir]. The reference lists of the retrieved studies were also manually searched to identify more qualified studies.

Inclusion and exclusion criteria. The inclusion criteria was as follows: i) Study design: Non-randomized and randomized controlled trial (RCT) studies were included; ii) study patients: Diagnosed with HBV related-HCC; iii) therapy for HCC: Curative resection or ablation; iv) antiviral treatment: Using NAs as regular therapy compared with placebo or no treatment in the control group following curative therapy of HCC; and v) results available on one of the following: 1-, 3- or 5 -year RFS or OS after surgery with antiviral therapy, HCC recurrence rate or mortality rate in the two groups. Exclusion criteria were as follows: i) Primary HCC was treated with palliative therapy (transarterial chemoembolization, radiation or systemic chemotherapy); and ii) trials including participants co-infected with other virus, such as HCV or human immunodeficiency virus (HIV).

Quality assessment. The quality of the included studies was assessed independently by two authors (Yuchen Zhou and Guosheng Yuan) using the Newcastle-Ottawa Scale (NOS) (6) for non-randomized studies. The NOS uses different tools for non-randomized studies and consists of 3 parameters of quality: Selection, comparability and exposure/outcome assessment. The NOS assigns a maximum of 4 points for selection, 2 for comparability and 3 for exposure/outcome. NOS scores of 1-3, 4-6 and 7-9 were assigned for low, intermediate and high-quality studies, respectively (7). Discrepancies were settled by consensus following joint re-evaluation of the original studies by the third author (Guangyao Zhou).

Data collection and statistical analysis. For each eligible manuscript, the following information was extracted: i) First author's name and year of publication, the country of patients and duration of the follow-up; ii) study design (randomized, case-control or cohort); iii) the exact NAs for antiviral therapy, iv) the included number of patients in the control and treatment group; v) the number of patients between the two groups in RFS or OS in 1-, 3- and 5-year, HCC recurrence or fatality; and vi) since numerous studies did not report this information directly, Kaplan-Meier curves were read by Engauge Digitizer version 4.1 (http://www.ohri.ca/programs/clinical_epidemiology/oxford.htm).

The relative ratio (RR) with a 95\% confidence interval (CI), using either a fixed-effect model or random-effect model, was

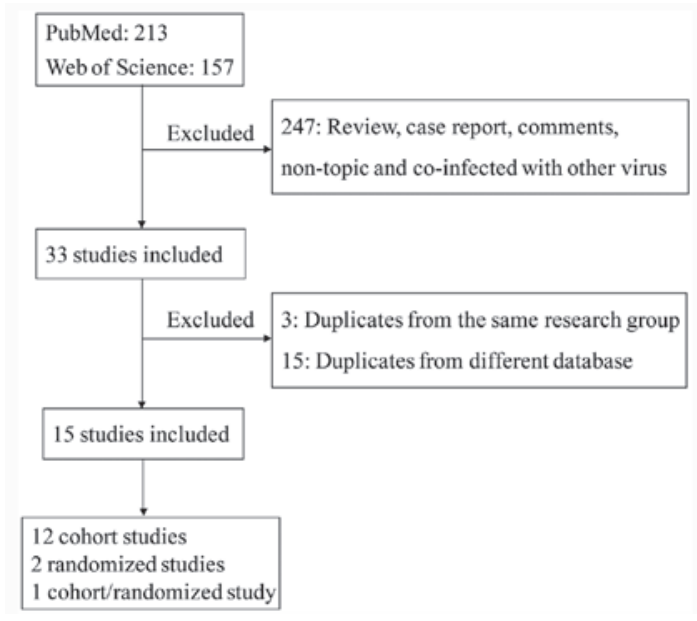

Figure 1. Flow diagram of study selection.

applied as a summary statistic for 1-, 3- and 5-year RFS/OS, $\mathrm{HCC}$ recurrence and fatalities between the two groups. In accordance with customary, an overall $\mathrm{RR}>1$ favored the NAs group in the survival rate and the control group in HCC recurrence and mortality rate. The difference was considered to indicate a statistical significance if the $95 \% \mathrm{CI}$ of the RR did not overlap 1, accompanied by $\mathrm{P}<0.05$.

Potential publication bias was comprehensively assessed by Begg's funnel plot and Egger's rank correlation test of asymmetry. Publication bias was determined present when the P-value was $\leq 0.10$ by the Egger's or Begg's test. Sensitivity analyses were used to evaluate the reliability of the results. All the statistical analyses were performed using STATA version 11.0 (STATA Corporation, College Station, TX, USA).

\section{Results}

Characteristics of included studies. In total, 388 citations were identified from the PubMed and Web of Science database. Following review by all the authors, there were 15 studies (8-22) (13 cohorts, 1 randomized and 1 randomized combined with cohort) that fulfilled the inclusion criteria (Fig. 1). The details are shown in Table I. In total there were 7,019 subjects included, with 1,353 patients in the antiviral treatment group and 5,266 in the control group. Based on the NOS scores, 13 of 14 studies (9 scores for 1 study, 8 scores for 6 studies and 7 scores for 6 studies) were of high quality and the other study (6 scores) was acceptable. The score of each study is presented in Table I. As the included randomized studies were not double-blind studies, these studies were low quality.

Effects of the intervention for the RFS and OS. Pooling the data of $11(8-11,13,14,17-19,21,22), 11(8-11,13,14,17-20,22)$ and $7(9-11,13,18,19,22)$ studies that assessed 1 -, 3 - and 5-year RFS (Table II and Fig. 2A-C) showed significant differences favoring NAs therapy (RR, 1.090; 95\% CI, 1.030-1.153; $\mathrm{P}=0.003$; RR, 1.202; 95\% CI, 1.121-1.288; $\mathrm{P}<0.001$; and $\mathrm{RR}, 1.219 ; 95 \% \mathrm{CI}, 1.032-1.442 ; \mathrm{P}=0.02$, respectively). The significant between-study heterogeneity only existed in the pooled analysis of 5-year RFS $\left(I^{2}=41.5 \%\right)$. In addition, as the randomized studies were low quality, the included cohort 
Table I. Characteristics of the included studies.

\begin{tabular}{|c|c|c|c|c|c|c|}
\hline Authors, year (Refs.) & NOS scores & $\begin{array}{c}\text { Data } \\
\text { collected }^{\mathrm{a}}\end{array}$ & Study design & Cure for HCC & Adjuvant treatment & $\begin{array}{c}\text { Sample size, } \\
\text { T/C }\end{array}$ \\
\hline Kuzuya et al, 2007 (17) & 7 & 1 & Cohort & Resection or RFA & LAM (with ADV rescue) & $141 / 141$ \\
\hline Kubo et al, 2007 (18) & 7 & 2 & Cohort & Resection & LAM (with ADV rescue) & $81 / 82$ \\
\hline Yoshida et al, 2008 (16) & 8 & 2 & Cohort & RFA & LAM (with ADV rescue) & $215 / 402$ \\
\hline Koda et al, 2009 (14) & 7 & 2 & Cohort & Resection or RFA & $\begin{array}{l}\text { LAM (with ADV or } \\
\text { ETV rescue) }\end{array}$ & $99 / 32$ \\
\hline Chuma et al, 2009 (15) & 8 & 1 & Cohort & Resection or RFA & $\begin{array}{l}\text { LAM (with ADV or } \\
\text { ETV rescue) }\end{array}$ & $14 / 10$ \\
\hline Chan et al, 2011 (13) & 7 & 1 & Cohort & Resection & LAM or ETV & $16 / 33$ \\
\hline Hann et al, 2011 (12) & 9 & 1 & Cohort & Resection or ablation & LAM, tenofovir or ADV & $42 / 94$ \\
\hline Wu et al, 2012 (11) & 8 & 2 & Cohort & Resection & LAM, ETV, telbivudin & $22 / 14$ \\
\hline Ke et al, 2013 (10) & 6 & 1 & Cohort & Resection & LAM & $9 / 6$ \\
\hline Yin et al, 2013 (8) & 8 & 2 & Cohort & Resection & $\begin{array}{l}\text { LAM (with ADV or } \\
\text { ETV rescue) }\end{array}$ & $39 / 64$ \\
\hline Su et al, 2013 (9) & 8 & 2 & Cohort & Resection & LAM OR ETV & $62 / 271$ \\
\hline Huang et al, 2013 (20) & 7 & 1 & Cohort & Resection & ADV, ETV or LAM & $518 / 4,051$ \\
\hline Nishikawa et al, 2014 (19) & 8 & 1 & Cohort & $\begin{array}{l}\text { Resection, RFA } \\
\text { or PCEI }\end{array}$ & LAM, ADV or ETV & $865 / 175$ \\
\hline Li et al, 2010 (21) & 7 & 1 & Cohort & Resection & $\begin{array}{l}\text { LAM (with or without } \\
\text { ADV) }\end{array}$ & $43 / 36$ \\
\hline Yin et al, 2013 (8) & Unclear bias & 2 & Randomized & Resection & $\begin{array}{l}\text { LAM (with ADV or } \\
\text { ETV rescue) }\end{array}$ & $33 / 71$ \\
\hline Huang et al, 2013 (22) & Unclear bias & 1 & Randomized & Resection & ADV & $100 / 100$ \\
\hline
\end{tabular}

${ }^{\mathrm{a}}$, data from the study; 2, data from the K-M survival by software. NOS, Newcastle-Ottawa Scale; HCC, hepatocellular carcinoma; T/C, treatment group/control group.

studies were pooled and analyzed. These studies also showed a significant benefit of 1- and 3-year RFS (RR 1.087; 95\% CI, 1.024-1.153; $\mathrm{P}=0.006$ and RR 1.186; 95\% CI, 1.104-1.273; $\mathrm{P}<0.001$ ), while there was no significant difference for the 5-year RFS (RR, 1.188; 95\% CI, 0.994-1.142; $\mathrm{P}=0.058$ ).

Pooling the data of $11(8-11,13,14,16,17,19,21,22)$, $10(8-11,13,14,16,17,19,22)$ and $6(9-11,13,19,22)$ studies that the assessed 3- and 5-year OS (Table II and Fig. 2D-F) showed significant differences favoring NAs therapy (RR, 1.106; 95\% CI, 1.045-1.171; $\mathrm{P}=0.001 ;$ and RR, 1.246; 95\% CI, 1.110-1.400; $\mathrm{P}<0.001)$, while no significant difference existed in the 1-year OS (RR, 1.029; 95\% CI, 0.980-1.081; $\mathrm{P}=0.249$ ). The significant between-study heterogeneity only existed in the pooled analysis of 5-year OS $\left(\mathrm{I}^{2}=33.3 \%\right)$. Additionally, as the randomized studies were low quality, the included cohorts were pooled and analyzed. These studies also showed the same results as above (1-year OS: RR, 1.028; 95\% CI, 0.977-1.083; $\mathrm{P}=0.289$, 3-year OS: RR, 1.096; 95\% CI, 1.033-1.163; $\mathrm{P}=0.003$ and 5-year OS: RR, 1.252; 95\% CI, 1.094-1.432; $\mathrm{P}=0.001$, respectively).

Effects of recurrence HCC and fatalities. Pooling data of $13(8-15,17-19,21,22)$ and $11(8-10,12,14,17-22)$ studies that assessed the rate of recurrence HCC and fatalities (Table III and Fig. 2G-H) showed a significantly higher rate in the control group (RR, 1.301; 95\% CI, 1.098-1.542; $\mathrm{P}=0.002$; and RR, 1.816; 95\% CI, 1.399-2.358; $\mathrm{P}<0.001)$. The significant between-study heterogeneity existed in the pooled analysis $\left(\mathrm{I}^{2}=55.2 \%\right.$ and $\left.\mathrm{I}^{2}=52.4 \%\right)$. In addition, as the randomized studies were low quality, the included cohorts were pooled and analyzed. These studies also showed the same results as above (recurrence HCC: RR, 1.328; 95\% CI, 1.069-1.650; $\mathrm{P}=0.011$; and fatalities: RR, 1.840; 95\% CI, 1.329-2.549; P<0.001).

Superior choice for antiviral treatment. One cohort study was included in this analysis (20). A total of $865 \mathrm{HBV}$-related HCC patients received antiviral treatment at diagnosis or immediately following surgery (adefovir at a dosage of $10 \mathrm{mg}$ /day in 300 patients, entecavir at a dosage of $0.5 \mathrm{mg} /$ day in 325 patients, and lamivudine at a dosage of $100 \mathrm{mg} / \mathrm{day}$ in 240 patients). The 1-, 2- and 3-year resistance rates were 0.9 , 1.8 and $2.5 \%$ for the entecavir group, 3.0, 8.3 and $12.0 \%$ for the adefovir group, and $21.7,31.7$ and $39.6 \%$ for the lamivudine group. The 3-year disease-free survival for the entecavir group was also significantly improved compared with the adefovir group and the lamivudine group (HR, 0.810; 95\% CI, 0.656-0.999; $\mathrm{P}=0.049$; and HR, 0.737; 95\% CI, 0.591-0.919; $\mathrm{P}=0.007)$.

Sensitivity analysis and publication bias. The sensitivity analyses were performed for the pooled RR and 95\% CI of the remaining researches by omitting each of the included studies. The results did not change and remained consistent with the pooled analyses as above (Fig. 3), except for the result 

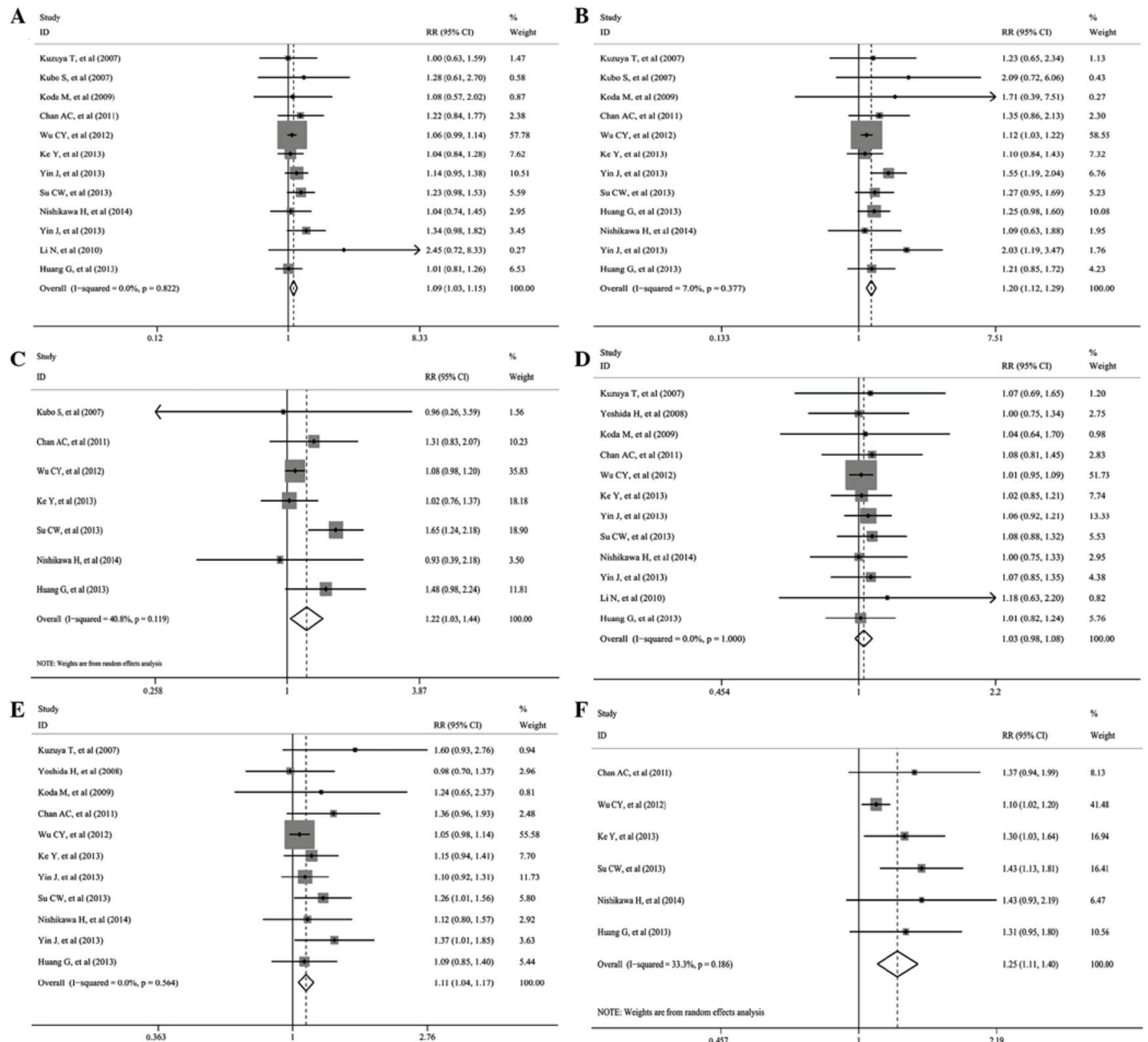

F sonty
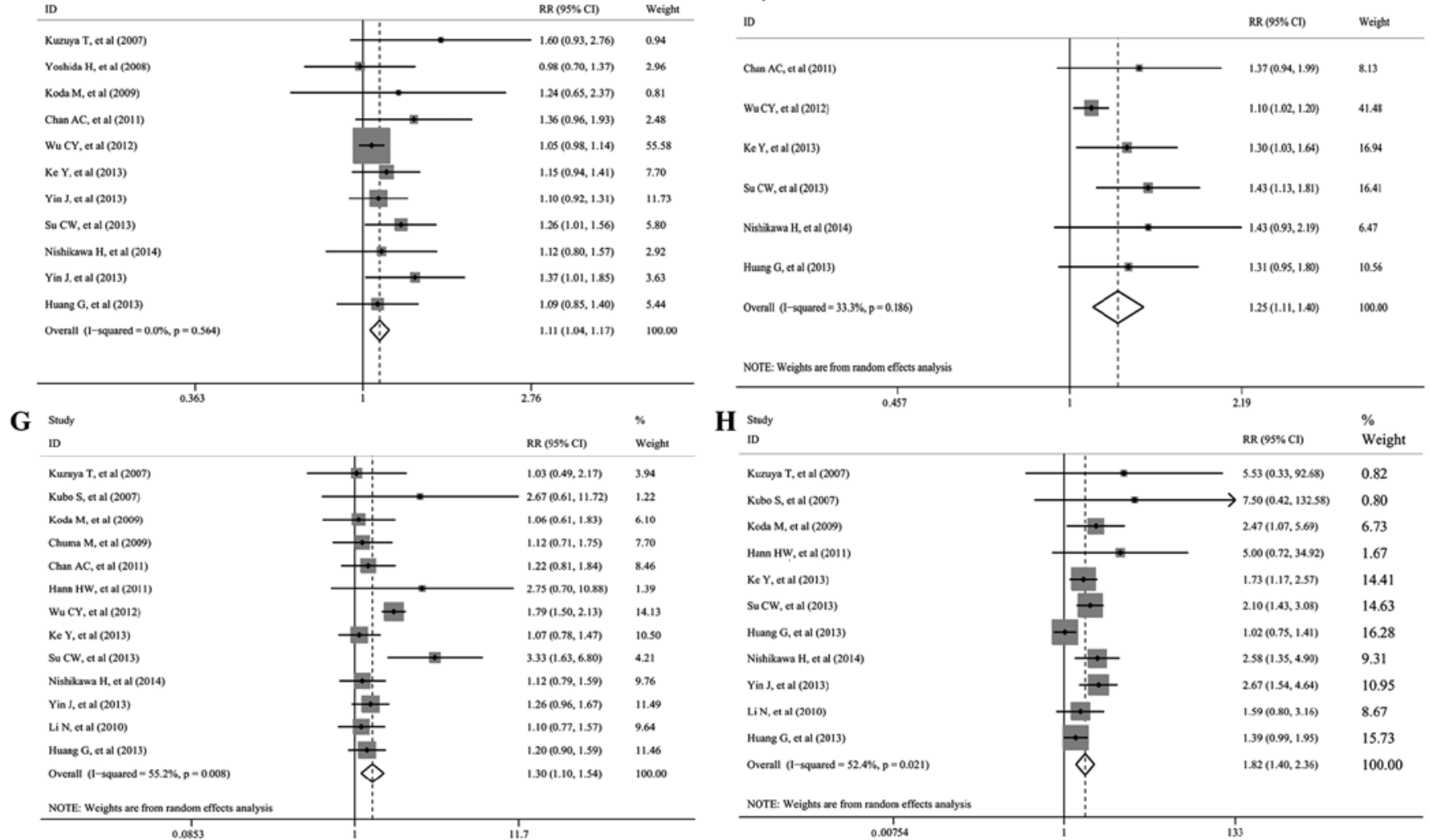

Figure 2. Forest plot of all the included studies on the treatment of nucleos(t)ide analogs (NAs) following curative treatment of hepatitis B virus (HBV)-related hepatocellular carcinoma (HCC). (A-C) Forest plot of recurrence free survival in 1-, 3- and 5-year (NAs versus control group). (D-F) Forest plot of overall survival in 1-, 3- and 5-year (NAs versus control group). (G and H) Forest plot of NAs therapy for recurrence HCC and fatalities (control versus NAs group).

of 5-year RFS, which had a significant difference within the randomized study of Huang et al (22), while there was no difference without the study. The results of publication bias analyzed by the Begg's test and Egger's test are shown in 
Table II. Pooled analysis of RFS and OS in 1-, 3- and 5-year.

\begin{tabular}{|c|c|c|c|c|c|c|c|c|}
\hline \multirow[b]{2}{*}{ Survival rate } & \multirow[b]{2}{*}{ Study design } & \multirow[b]{2}{*}{$\begin{array}{l}\text { No. of } \\
\text { studies }\end{array}$} & \multirow[b]{2}{*}{ RR $(95 \% \mathrm{CI})$} & \multirow[b]{2}{*}{ P-value } & \multirow[b]{2}{*}{$\mathrm{I}^{2}, \%$} & \multicolumn{2}{|c|}{ Publication bias } & \multirow[b]{2}{*}{ Model } \\
\hline & & & & & & $\begin{array}{l}\text { Egger's } \\
\text { test }\end{array}$ & $\begin{array}{l}\text { Begg's } \\
\text { test }\end{array}$ & \\
\hline \multicolumn{9}{|l|}{ RFS } \\
\hline 1-year & $\begin{array}{l}\text { Cohort } \\
\text { Cohort/randomized }\end{array}$ & $\begin{array}{l}10 \\
11\end{array}$ & $\begin{array}{l}1.087(1.024-1.153) \\
1.090(1.030-1.153)\end{array}$ & $\begin{array}{l}0.006 \\
0.003\end{array}$ & $\begin{array}{l}0.0 \\
0.0\end{array}$ & $\begin{array}{l}0.102 \\
0.080\end{array}$ & $\begin{array}{l}0.152 \\
0.150\end{array}$ & $\begin{array}{l}\text { Fixed-effect } \\
\text { Fixed-effect }\end{array}$ \\
\hline 3-year & $\begin{array}{l}\text { Cohort } \\
\text { Cohort/randomized }\end{array}$ & $\begin{array}{l}10 \\
12\end{array}$ & $\begin{array}{l}1.186(1.104-1.273) \\
1.202(1.121-1.288)\end{array}$ & $\begin{array}{l}<0.001 \\
<0.001\end{array}$ & $\begin{array}{l}0.0 \\
7.0\end{array}$ & $\begin{array}{l}0.060 \\
0.024\end{array}$ & $\begin{array}{l}0.474 \\
0.304\end{array}$ & $\begin{array}{l}\text { Fixed-effect } \\
\text { Fixed-effect }\end{array}$ \\
\hline 5-year & $\begin{array}{l}\text { Cohort } \\
\text { Cohort/randomized }\end{array}$ & $\begin{array}{l}6 \\
7\end{array}$ & $\begin{array}{l}1.188(0.994-1.420) \\
1.219(1.032-1.442)\end{array}$ & $\begin{array}{l}0.058 \\
0.020\end{array}$ & $\begin{array}{l}41.5 \\
40.8\end{array}$ & $\begin{array}{l}0.644 \\
0.447\end{array}$ & $\begin{array}{l}0.707 \\
0.881\end{array}$ & $\begin{array}{l}\text { Random-effect } \\
\text { Random-effect }\end{array}$ \\
\hline \multicolumn{9}{|l|}{ OS } \\
\hline 1-year & $\begin{array}{l}\text { Cohort } \\
\text { Cohort/randomized }\end{array}$ & $\begin{array}{l}10 \\
11\end{array}$ & $\begin{array}{l}1.028(0.977-1.083) \\
1.029(0.980-1.081)\end{array}$ & $\begin{array}{l}0.289 \\
0.249\end{array}$ & $\begin{array}{l}0.0 \\
0.0\end{array}$ & $\begin{array}{l}0.112 \\
0.082\end{array}$ & $\begin{array}{l}0.371 \\
0.631\end{array}$ & $\begin{array}{l}\text { Fixed-effect } \\
\text { Fixed-effect }\end{array}$ \\
\hline 3-year & $\begin{array}{l}\text { Cohort } \\
\text { Cohort/randomized }\end{array}$ & $\begin{array}{r}9 \\
10\end{array}$ & $\begin{array}{l}1.096(1.033-1.163) \\
1.106(1.045-1.171)\end{array}$ & $\begin{array}{l}0.003 \\
0.001\end{array}$ & $\begin{array}{l}0.0 \\
0.0\end{array}$ & $\begin{array}{l}0.040 \\
0.019\end{array}$ & $\begin{array}{l}0.348 \\
0.213\end{array}$ & $\begin{array}{l}\text { Fixed-effect } \\
\text { Fixed-effect }\end{array}$ \\
\hline 5-year & $\begin{array}{l}\text { Cohort } \\
\text { Cohort/randomized }\end{array}$ & $\begin{array}{l}5 \\
6\end{array}$ & $\begin{array}{l}1.252(1.094-1.432) \\
1.246(1.110-1.400)\end{array}$ & $\begin{array}{r}0.001 \\
<0.001\end{array}$ & $\begin{array}{l}42.9 \\
33.3\end{array}$ & $\begin{array}{l}0.024 \\
0.009\end{array}$ & $\begin{array}{l}0.806 \\
0.452\end{array}$ & $\begin{array}{l}\text { Random-effect } \\
\text { Random-effect }\end{array}$ \\
\hline
\end{tabular}

RFS, recurrence-free survival; OS, overall survival; RR, relative risk; CI, confidence interval.

Table III. Pooled analysis of recurrent HCC and fatalities.

\begin{tabular}{|c|c|c|c|c|c|c|c|c|}
\hline \multirow[b]{2}{*}{ Outcome } & \multirow[b]{2}{*}{ Study design } & \multirow[b]{2}{*}{$\begin{array}{l}\text { No. of } \\
\text { studies }\end{array}$} & \multirow[b]{2}{*}{ RR $(95 \%$ CI $)$} & \multirow[b]{2}{*}{ P-value } & \multirow[b]{2}{*}{$\mathrm{I}^{2}, \%$} & \multicolumn{2}{|c|}{ Publication bias } & \multirow[b]{2}{*}{ Model } \\
\hline & & & & & & $\begin{array}{c}\text { Egger's } \\
\text { test }\end{array}$ & $\begin{array}{c}\text { Begg's } \\
\text { test }\end{array}$ & \\
\hline Recurrent HCC & Cohort & 11 & $1.328(1.069-1.650)$ & 0.011 & 60.5 & 0.723 & 0.213 & Random-effect \\
\hline Fatalities & $\begin{array}{l}\text { Cohort/randomized } \\
\text { Cohort } \\
\text { Cohort/randomized }\end{array}$ & $\begin{array}{r}13 \\
9 \\
11\end{array}$ & $\begin{array}{l}1.301(1.098-1.542) \\
1.840(1.329-2.549) \\
1.816(1.399-2.358)\end{array}$ & $\begin{array}{r}0.002 \\
<0.001 \\
<0.001\end{array}$ & $\begin{array}{l}55.2 \\
53.1 \\
52.4\end{array}$ & $\begin{array}{l}0.771 \\
0.056 \\
0.029\end{array}$ & $\begin{array}{l}0.360 \\
0.754 \\
0.350\end{array}$ & $\begin{array}{l}\text { Random-effect } \\
\text { Random-effect } \\
\text { Random-effect }\end{array}$ \\
\hline
\end{tabular}

RR, relative risk; HCC, hepatocellular carcinoma.

Tables I and II. Publication bias was found according to the Begg's test and Egger's test in the 3-year RFS, OS and the rate of fatalities (Tables II and III and Fig. 4).

\section{Discussion}

In the present meta-analysis, 15 studies fulfilled the criteria. The results showed the significant benefits of NAs therapy for RFS, OS, recurrence HCC and fatalities, respectively. Sensitivity analysis also confirmed the robustness of the results.

In view of the established association between high HBV DNA viral load and HCC recurrence and fatalities, inhibiting $\mathrm{HBV}$ replication by antiviral therapy should theoretically be able to prevent this condition. Recently, certain meta-analysis studies have shown that postoperative antiviral therapy with NAs can reduce HCC recurrence and mortality $(23,24)$. However, few analyses have shown that the antiviral treatment can improve the survival rate in different years for patients following curative treatment, except for the study in 2010 (25). Overall, the present pooled results were similar with previous studies (23-25), which revealed that NAs therapy can significantly delay the disease progression of HBV-related HCC following resection. The results from the study have demonstrated that NAs treatment following curative resection of $\mathrm{HBV}$-related $\mathrm{HCC}$ reduced recurrences, mortality and improved the survival rate. The main beneficial effect of NAs is associated with its prevention of viral replication-related carcinogenesis. Additionally, suppression of $\mathrm{HBV}$ replication could improve remnant liver function, which would decrease the mortality due to liver failure and allow subsequently aggressive treatment for recurrences (17). However, some of the pooled analysis, such as 5-year RFS and 1-year OS, were insufficient. Although these results had no clear difference between patients in the antiviral treatment and control groups, they were nearly the cut-off value. Therefore, more original studies are required to be conducted for these purposes. 
A

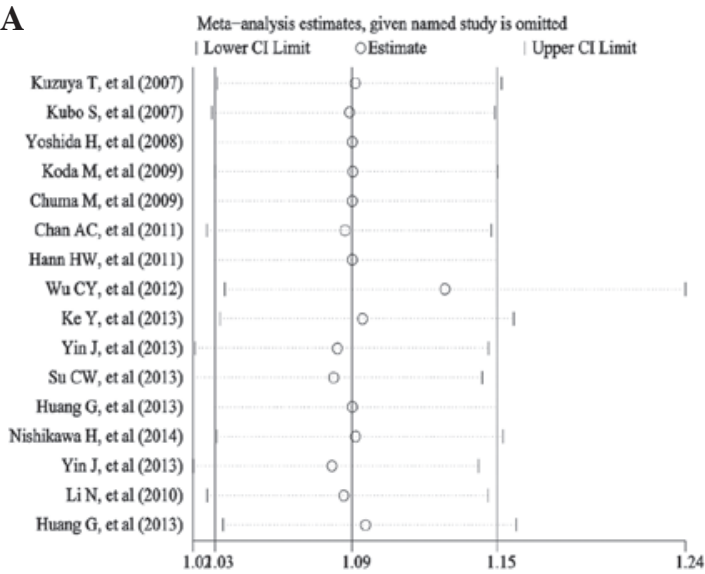

C

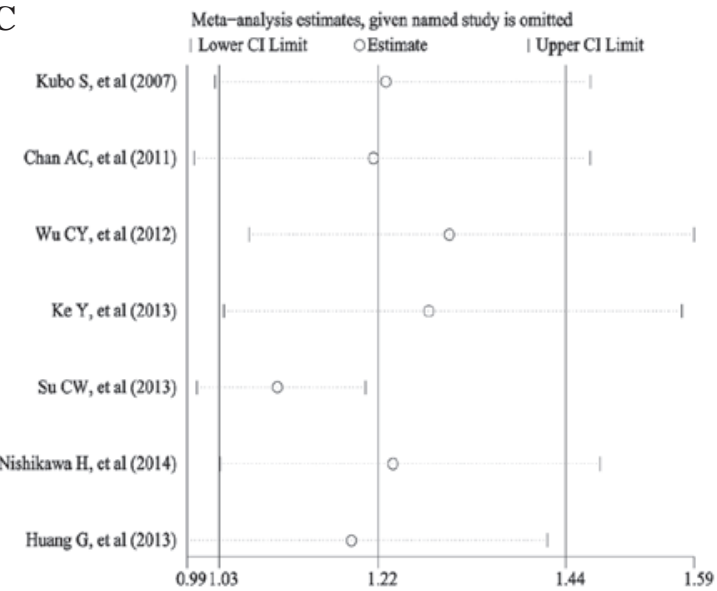

$\mathbf{E}$
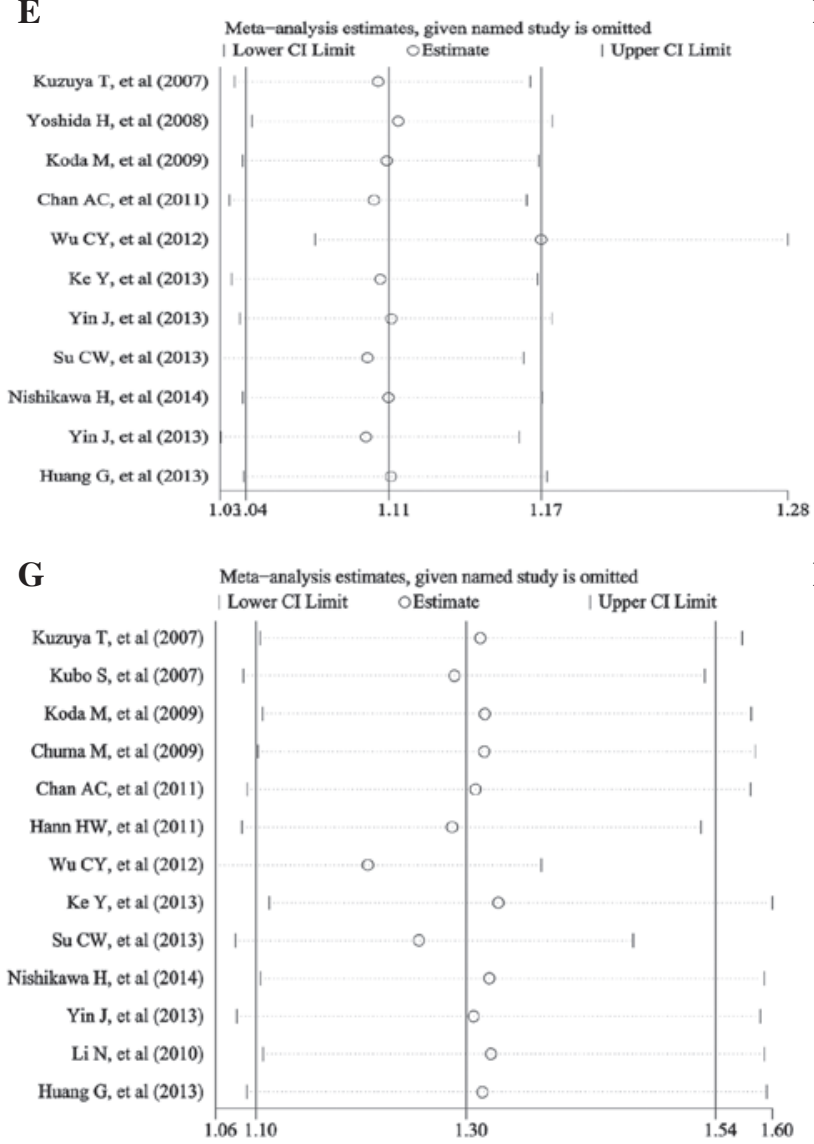

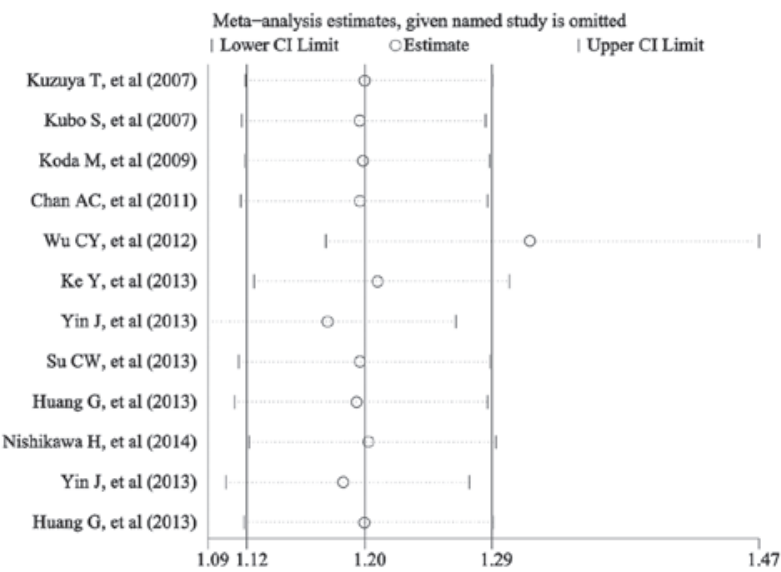

D

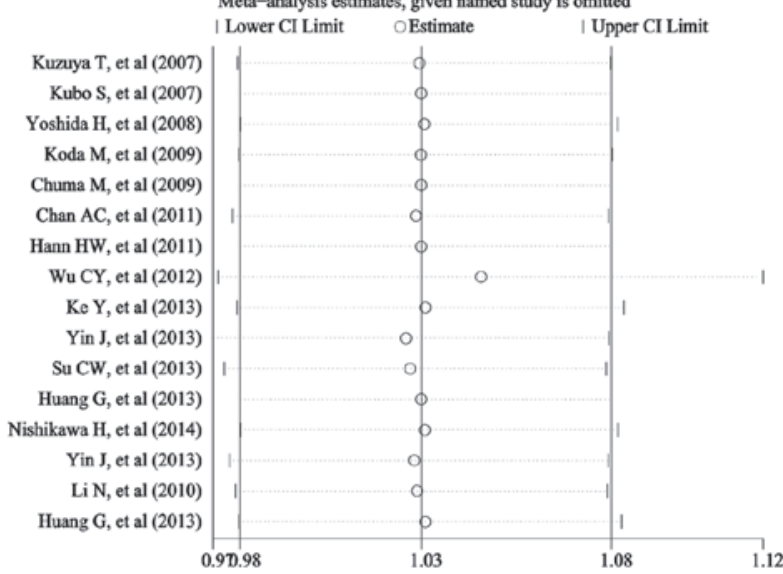

$\mathbf{F}$

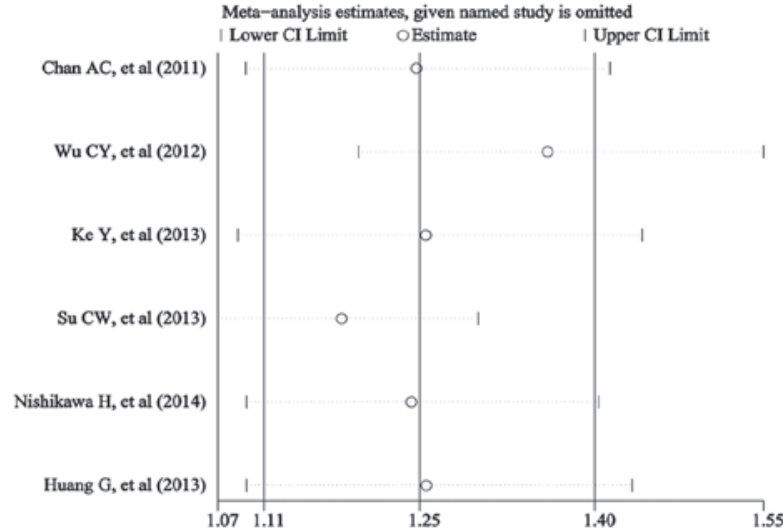

H

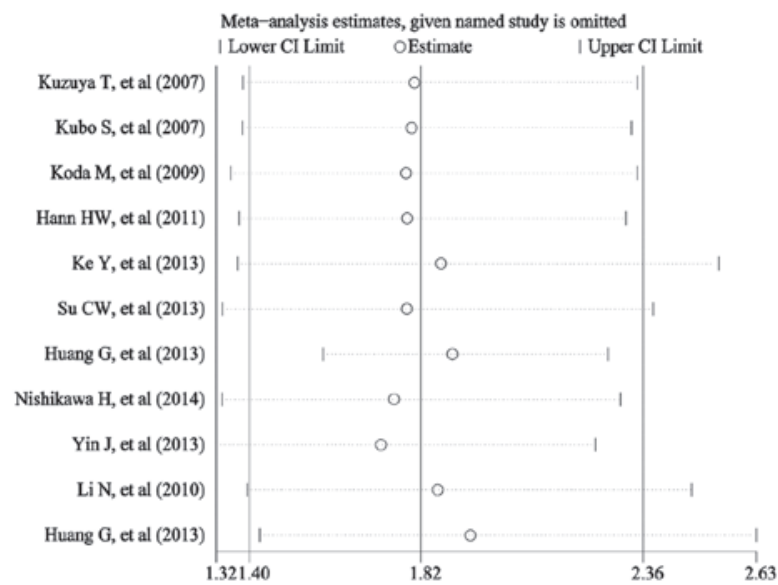

Figure 3. Sensitivity analyses of all the included studies on the nucleos(t)ide analogs (NAs) therapy of hepatitis B virus (HBV)-related hepatocellular carcinoma (HCC). (A-C) Sensitivity analyses of recurrence-free survival at 1-, 3- and 5-year. (D-F) Sensitivity analyses of overall survival at 1-, 3- and 5-year. $(\mathrm{G}$ and $\mathrm{H})$ Sensitivity analyses of NAs therapy for recurrent HCC and fatalities. CI, confidence interval. 

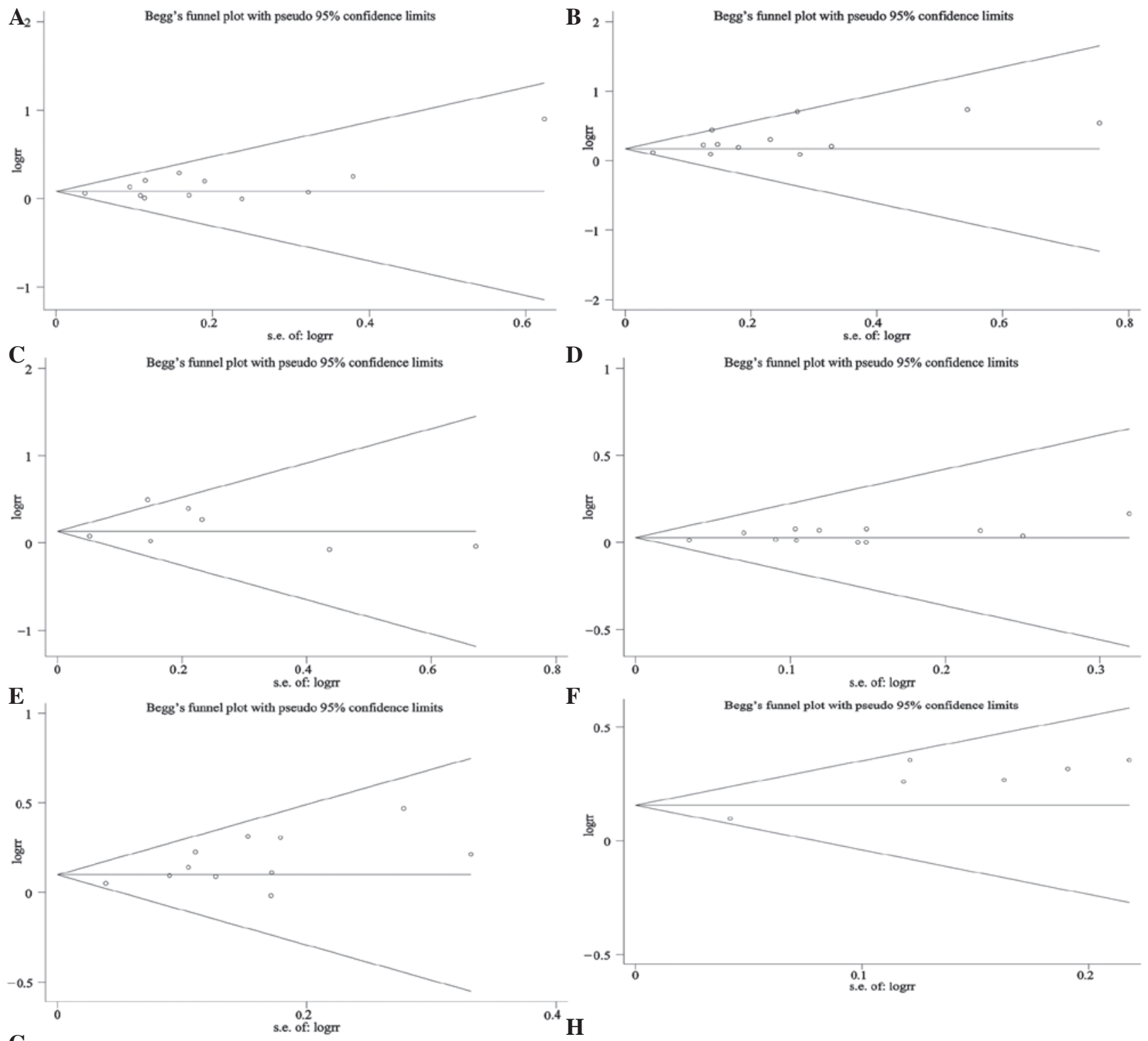

G

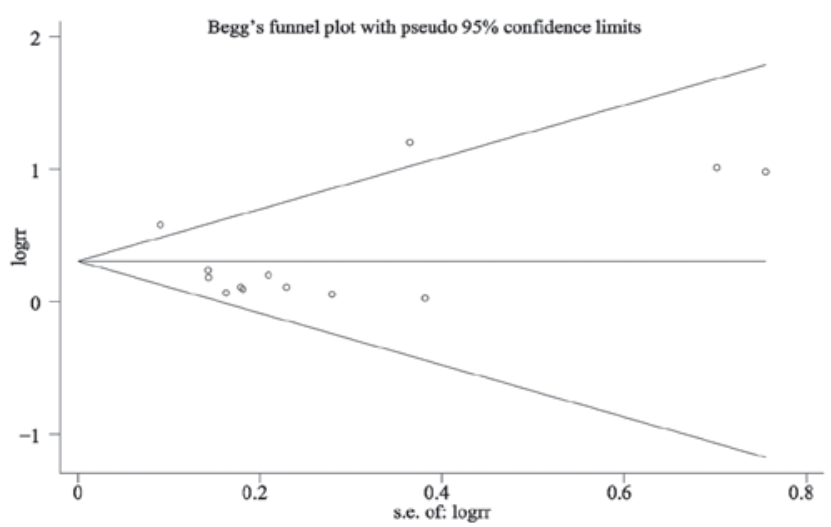

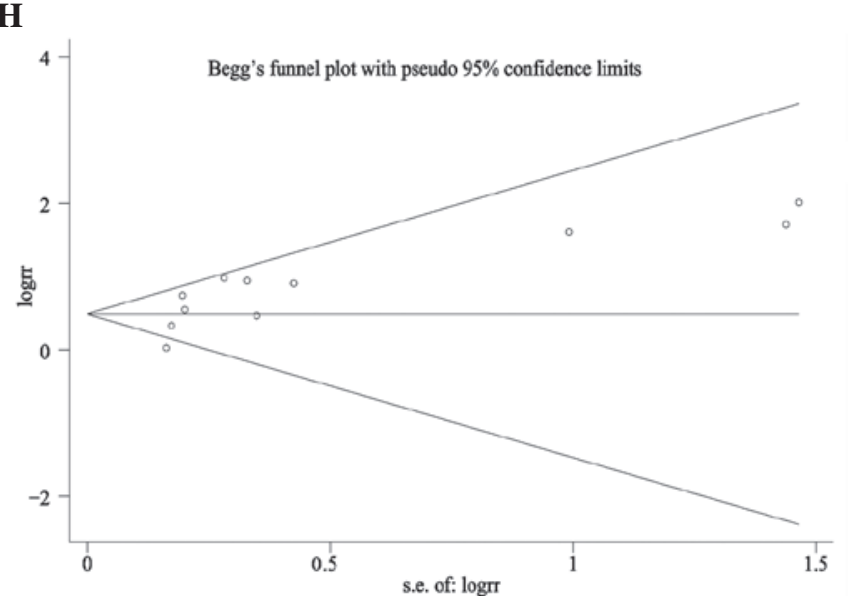

Figure 4. Funnel plot of all the included studies for assessing publication bias. (A-C) Funnel plot of recurrence free survival at 1-, 3- and 5-year. (D-F) Funnel plot of overall survival at 1-, 3- and 5-year. ( $\mathrm{G}$ and $\mathrm{H}$ ) Funnel plot of nucleos(t)ide analogs (NAs) therapy for recurrent hepatocellular carcinoma (HCC) and fatalities.

Only one study showed the different effects with ETV, LAM and ADV (20). ETV is a superior choice for HBV-related HCC patients following curative treatment compared with the patients with LAM and ADV treatment, which is based on the lower resistance rate and higher RFS. The combination of ETV plus low-dose on-demand hepatitis B immunoglobulin (HBIG) is effective with extremely low hepatitis B recurrence following liver transplantation, compared with patients on combination of LAM and HBIG (26). As known, ETV is one of the first-line drugs for treatment of HBV patients, even for patients 
with ADV resistance (27). For the patients with HBV-related cirrhosis, ETV shows the higher efficacy in viral suppression and a lower risk of antiviral resistance $(28,29)$. Treatment with ETV also showed that it could reduce the incidence of HCC in HBV-infected patients (30). Although, only one study was included in the present analysis, ETV may be the better choice compared with LAM or ADV for HBV-related HCC patients following curative treatment, without economic consideration.

Regarding the sensitivity analysis for the 5-year RFS, two different results were observed. The significant difference existed when the randomized study of Huang et al (22) was pooled. By contrast, no difference was observed. This may have been caused by two reasons. First, the pooled analysis had heterogeneity, which impaired the result. Second, the number of included patients was not sufficient. Thus, more studies are required to be investigated in the future.

Certain limitations of the study should be listed. First, all the included studies were non-randomized trials except two studies, but the results still showed significant benefits of NAs therapy and were stable according to sensitivity analysis. Second, significant between-study heterogeneity existed in the pooled results of 5-year RFS, 5-year OS, recurrence HCC and fatalities, which may be a result of the different patients, the type of NAs and duration of treatment. In the present meta-analysis, the pooled data neglected the differences, so a random-effect model was applied. Third, a certain extent of publication bias existed despite no statistical significance by Egger's test, such as 3-year RFS, 3-year OS, 5-year OS and fatalities, which may indicate a type of unpredictable report bias. Fourth, certain data were transformed from a survival curve, instead of as reported, which can lead to bias.

In conclusion, despite the limitations listed above, the present study demonstrated beneficial effects of NAs therapy following curative treatment of HBV-related HCC. ETV may be the superior choice of antiviral treatment. Further studies should focus on which type of NA drugs are beneficial for patients following curative treatment of HBV-related HCC.

\section{Acknowledgements}

The present study was supported by grants from the National Science Foundation of China (no. 81470856) and the Chinese Foundation for Hepatitis Prevention and Control (no. XJS20120601).

\section{References}

1. Jemal A, Bray F, Center MM, Ferlay J, Ward E and Forman D: Global cancer statistics. CA Cancer J Clin 61: 69-90, 2011.

2. Papatheodoridis GV, Lampertico P, Manolakopoulos S and Lok A: Incidence of hepatocellular carcinoma in chronic hepatitis B patients receiving nucleos(t)ide therapy: A systematic review. J Hepatol 53: 348-356, 2010.

3. Zhou Y, Sui C, Li B, Yin Z, Tan Y, Yang J and Liu Z: Repeat hepatectomy for recurrent hepatocellular carcinoma: A local experience and a systematic review. World J Surg Oncol 8: 55, 2010.

4. Sun P, Dong X, Cheng X, Hu Q and Zheng Q: Nucleot(s)ide analogues for hepatitis B virus-related hepatocellular carcinoma after curative treatment: A systematic review and meta-analysis. PLoS One 9: e102761, 2014.

5. Moher D, Liberati A, Tetzlaff J and Altman DG; PRISMA Group: Preferred reporting items for systematic reviews and meta-analyses: The PRISMA statement. PLoS Med 6: e1000097, 2009.
6. Wells GA, Shea B, O'Connell D, Peterson J, Welch V, Losos M and Tugwell P: The Newcastle-Ottawa Scale (NOS) for assessing the quality of nonrandomised studies in meta-analyses. Ottawa Hospital Research Institute, 2012. http://www.ohri. ca/programs/clinical_epidemiology/oxford.asp. Accessed, October, 19, 2009.

7. Zhang H, Zhou YP, Peng HJ, Zhang XH, Zhou FY, Liu ZH and Chen XG: Predictive symptoms and signs of severe dengue disease for patients with dengue fever: A meta-analysis. Biomed Res Int 2014: 359308, 2014.

8. Yin J, Li N, Han Y, Xue J, Deng Y, Shi J, Guo W, Zhang H, Wang $\mathrm{H}$, Cheng $\mathrm{S}$, et al: Effect of antiviral treatment with nucleotide/nucleoside analogs on postoperative prognosis of hepatitis B virus-related hepatocellular carcinoma: A two-stage longitudinal clinical study. J Clin Oncol 31: 3647-3655, 2013.

9. Su CW, Chiou YW, Tsai YH, Teng RD, Chau GY, Lei HJ, Hung HH, Huo TI and Wu JC: The influence of hepatitis B viral load and pre-S deletion mutations on post-operative recurrence of hepatocellular carcinoma and the tertiary preventive effects by anti-viral therapy. PLoS One 8: e66457, 2013.

10. Ke Y, Ma L, You XM, Huang SX, Liang YR, Xiang BD, Li LQ and Zhong JH: Antiviral therapy for hepatitis B virus-related hepatocellular carcinoma after radical hepatectomy. Cancer Biol Med 10: 158-164, 2013.

11. Wu CY, Chen YJ, Ho HJ, Hsu YC, Kuo KN, Wu MS and Lin JT: Association between nucleoside analogues and risk of hepatitis B virus-related hepatocellular carcinoma recurrence following liver resection. JAMA 308: 1906-1914, 2012.

12. Hann HW, Bergin D, Coben R and DiMarino AJ: Prevention of new hepatocellular carcinoma with concomitant antiviral therapy in chronic hepatitis B patients whose initial tumor was successfully ablated. Int J Cancer 128: 739-742, 2011.

13. Chan AC, Chok KS, Yuen WK, Chan SC, Poon RT, Lo CM and Fan ST: Impact of antiviral therapy on the survival of patients after major hepatectomy for hepatitis B virus-related hepatocellular carcinoma. Arch Surg 146: 675-681, 2011.

14. Koda M, Nagahara T, Matono T, Sugihara T, Mandai M, Ueki M, Ohyama K, Hosho K, Okano J, Kishimoto Y, et al: Nucleotide analogs for patients with HBV-related hepatocellular carcinoma increase the survival rate through improved liver function. Intern Med 48: 11-17, 2009.

15. Chuma M, Hige S, Kamiyama T, Meguro T, Nagasaka A, Nakanishi K, Yamamoto Y, Nakanishi M, Kohara T, Sho T, et al: The influence of hepatitis B DNA level and antiviral therapy on recurrence after initial curative treatment in patients with hepatocellular carcinoma. J Gastroenterol 44: 991-999, 2009.

16. Yoshida H, Yoshida H, Goto E, Sato T, Ohki T, Masuzaki R, Tateishi R, Goto T, Shiina S, Kawabe T, et al: Safety and efficacy of lamivudine after radiofrequency ablation in patients with hepatitis B virus-related hepatocellular carcinoma. Hepatol Int 2: 89-94, 2008.

17. Kuzuya T, Katano Y, Kumada T, Toyoda H, Nakano I, Hirooka Y, Itoh A, Ishigami M, Hayashi K, Honda T, et al: Efficacy of antiviral therapy with lamivudine after initial treatment for hepatitis B virus-related hepatocellular carcinoma. J Gastroenterol Hepatol 22: 1929-1935, 2007.

18. Kubo S, Tanaka H, Takemura S, Yamamoto S, Hai S, Ichikawa T, Kodai S, Shinkawa H, Sakaguchi H, Tamori A, et al: Effects of lamivudine on outcome after liver resection for hepatocellular carcinoma in patients with active replication of hepatitis B virus. Hepatol Res 37: 94-100, 2007.

19. Nishikawa H, Nishijima N, Arimoto A, Inuzuka T, Kita R, Kimura $\mathrm{T}$ and Osaki Y: Effect of nucleoside analog use in patients with hepatitis B virus-related hepatocellular carcinoma. Hepatol Res 44: 608-620, 2014.

20. Huang G, Yang Y, Shen F, Pan ZY, Fu SY, Lau WY, Zhou WP and Wu MC: Early viral suppression predicts good postoperative survivals in patients with hepatocellular carcinoma with a high baseline HBV-DNA load. Ann Surg Oncol 20: 1482-1490, 2013.

21. Li N, Lai EC, Shi J, Guo WX, Xue J, Huang B, Lau WY, Wu MC and Cheng SQ: A comparative study of antiviral therapy after resection of hepatocellular carcinoma in the immune-active phase of hepatitis B virus infection. Ann Surg Oncol 17: 179-185, 2010.

22. Huang L, Li J, Yan J, Sun J, Zhang X, Wu M and Yan Y: Antiviral therapy decreases viral reactivation in patients with hepatitis $B$ virus-related hepatocellular carcinoma undergoing hepatectomy: A randomized controlled trial. J Viral Hepat 20: 336-342, 2013.

23. Zhou Y, Zhang Z, Zhao Y, Wu L and Li B: Antiviral therapy decreases recurrence of hepatitis B virus-related hepatocellular carcinoma after curative resection: A meta-analysis. World J Surg 38: 2395-2402, 2014. 
24. Wong JS, Wong GL, Tsoi KK, Wong VW, Cheung SY, Chong CN, Wong J, Lee KF, Lai PB and Chan HL: Meta-analysis: The efficacy of anti-viral therapy in prevention of recurrence after curative treatment of chronic hepatitis B-related hepatocellular carcinoma. Aliment Pharmacol Ther 33: 1104-1112, 2011

25. Miao RY, Zhao HT, Yang HY, Mao YL, Lu X, Zhao Y, Liu CN, Zhong SX, Sang XT and Huang JF: Postoperative adjuvant antiviral therapy for hepatitis B/C virus-related hepatocellular carcinoma: A meta-analysis. World J Gastroenterol 16: 2931-2942, 2010.

26. Hu TH, Chen CL, Lin CC, Wang CC, Chiu KW, Yong CC, Liu YW and Eng HL: Section 14. Combination of entecavir plus low-dose on-demand hepatitis B immunoglobulin is effective with very low hepatitis B recurrence after liver transplantation. Transplantation 97 (Suppl 8): S53-S59, 2014.

27. European Association For The Study Of The Liver: EASL clinical practice guidelines: Management of chronic hepatitis B virus infection. J Hepatol 57: 167-185, 2012.
28. Kim HR, Yim HJ, Kang S, Suh SJ, Kim SY, Hyun JJ, Koo JS, Kim JH, Seo YS, Yeon JE, et al: Efficacy of telbivudine compared with entecavir in hepatitis B virus-related cirrhosis: 2 year follow-up data. Liver Int 35: 860-869, 2014.

29. Ye XG and Su QM: Effects of entecavir and lamivudine for hepatitis B decompensated cirrhosis: Meta-analysis. World J Gastroenterol 19: 6665-6678, 2013.

30. Hosaka T, Suzuki F, Kobayashi M, Seko Y, Kawamura Y, Sezaki H, Akuta N, Suzuki Y, Saitoh S, Arase Y, et al: Long-term entecavir treatment reduces hepatocellular carcinoma incidence in patients with hepatitis B virus infection. Hepatology 58: 98-107, 2013 